\title{
ÉTICA E DELIBERAÇÃO PRÁTICA. AS NARRATIVAS DOS EDUCADORES SOCIAIS
}

\section{Ethics and practical deliberation. The social educator's narratives}

\author{
Evangelina Bonifácio \\ Centro de Estudos para o Desenvolvimento Humano (CEDH) \\ Instituto Politécnico de Bragança/ESE \\ Correo-e: evangelina@ipb.pt \\ Isabel BAPTISTA \\ Centro de Estudos para o Desenvolvimento Humano (CEDH) \\ Universidade Católica Portuguesa/FEP \\ Correo-e: ibaptista@porto.ucp.pt
}

Recibido: 17 de febrero de 2020

Envío a informantes: 28 de febrero de 2020

Aceptación definitiva: is de abril de 2020

Resumo: Este texto apresenta os resultados de parte de um estudo realizado junto de um grupo de educadores sociais portugueses visando compreender de que forma estes técnicos da ação socioeducativa lidam com as questões éticas emergentes do seu quotidiano profissional. Para o efeito, recorreu-se a uma estratégia de investigação assente na recolha de narrativas produzidas pelos próprios atores, em alinhamento com uma conceção de ética prática de teor eminentemente dialógico e relacional. Tal como será sublinhado, os resultados recolhidos e analisados evidenciam necessidades específicas de formação ético-deontológica, com ênfase para as aptidões de deliberação em contexto.

Palavras-chave: educadores sociais; ética socioeducacional; conhecimento profissional; deliberação prática.

AвstRACt: This text presents the results of a study part carried out with a group of Portuguese social educators following understand how these technicians of socio-educational action deal with the emerging ethical issues of your daily professional life. To 
that end, we tried a strategy of research based on the collection of narratives produced by the unique actors in alignment with an ethical practice of eminently dialogical and relational content. As will be underlined, the results collected and analyzed specific ethical-deontological training needs, with emphasis on deliberative skills in context.

KeY wORDs: social educators; socio-educational ethics; knowledge professional; practical deliberation.

\section{Introdução}

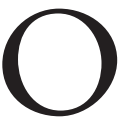

S EDUCADORES SOCIAIS, enquanto profissionais da intervenção socioeducativa vocacionados para a atuação junto de pessoas e grupos humanos em situação de exclusão ou vulnerabilidade, enfrentam, diariamente, situações de grande complexidade e que, de modo muito particular, apelam ao desenvolvimento de aptidões de deliberação prática consonantes com a sua responsabilidade ético-profissional (Baptista, 20I2).

Neste entendimento, o estudo teve como objetivo fundamental compreender de que forma os educadores sociais percecionam, verbalizam e refletem sobre os problemas e os dilemas de natureza ética que surgem no seu dia-a-dia, em contexto de relação com os educandos, com os colegas de trabalho e com outros atores profissionais e institucionais. Neste artigo, são expostos dados e conclusões referentes a parte desse estudo, destacando elementos de consciência ético-profissional convocados no âmbito dos processos decisionais vividos em contexto.

Assim, tomando como base de referência os pressupostos teóricos e metodológicos que sustentaram o projeto europeu ESEP (European Social Ethics Project) desenvolvido durante o ano de 1998 sob o enquadramento da FESET (European Social Education Training) e no qual participaram autores portugueses (Banks e Norh, 2008), procedeu-se à recolha de testemunhos de experiência e reflexão junto de um grupo de educadores sociais considerado significativo. Estes testemunhos foram produzidos ao longo de dois meses (março-abril, 20I9), tendo por base um guião e um protocolo celebrado com os participantes que, para tal, deram o seu consentimento, após terem sido devidamente informados e esclarecidos sobre todos os aspetos relativos à sua participação.

\section{2. Ética e conhecimento profissional}

Constituindo-se como um saber eminentemente ético e estético, indexado aos valores de humanismo relacional que caracterizam a utopia do humano no século XXI (Baptista, 20I2), a Pedagogia Social corresponde ao conhecimento profissional de referência dos educadores sociais, inspirando decisivamente as suas práticas. Como tal, importa cuidar das condições de desenvolvimento do conhecimento ético dos educadores sociais, aqui associado à capacidade pessoal e profissional que impele cada sujeito a examinar criticamente a sua própria conduta, questionando intenções e ações (Campbell, 20II: 82).

Do nosso ponto de vista, esta exigência de reflexividade ética surge reforçada quando em causa está a ação sociopedagógica, onde as dimensões de deliberação em 
contexto e em relação assumem particular relevância. Situamo-nos desta forma no campo da chamada ética prática ou ética aplicada, adotando, neste caso, uma conceção de ética relacional balizada pelo princípio da hospitalidade, tal como vem sendo trabalhado no âmbito de uma «ética do rosto», inspirada na filosofia de Emmanuel Lévinas (Baptista, 2016, 2017).

\section{Opções metodológicas}

\section{I. As narrativas profissionais como prática investigativa}

Associando o perfil do educador social à noção de «profissional reflexivo», em linha com o pensamento de Schön $(1995,2000)$ e reconhecendo a importância da escrita profissional na promoção de reflexividade ética, optou-se por uma metodologia assente na análise qualitativa de um conjunto de narrativas profissionais. Desenvolvida em forma de diário de bordo ou de memória descritiva, a escrita profissional permite desenvolver a consciencialização sobre as situações complexas vividas no quotidiano, potenciando a «capacidade para questionar as causas e estabelecer conexões» (Banks, 2008: 60). O que, desta forma, se revela consonante com a definição e conhecimento ético anteriormente enunciada.

Por outro lado, estando em referência um campo de ação profissional assente numa prática de relação humana tão relevante e específica, como é a educação social, entendemos que importa procurar escutar as razões dos próprios atores de forma a valorizar a sua «condição de rosto» e o seu «poder de assinatura» (Baptista, 20I2). Neste sentido, concordamos com Pineau e Le Grand (2002) quando referem a importância de dar voz aos sujeitos, salientando que as histórias de vida são fundamentais nos processos de autoformação, dado que não visam «apenas a teorização das práticas empíricas, mas a articulação dialética dos dois polos: prática e teoria» (p. I8).

Com estes pressupostos metodológicos em referência, a estratégia investigativa contemplou os seguintes passos:

a. Identificação e seleção do grupo de participantes-educadores sociais com experiência profissional em diferentes contextos laborais e disponíveis.

b. Reunião com os participantes selecionados, em registo de grupo de focagem, para explicação sobre objetivos do estudo e estratégia de desenvolvimento. Celebraram protocolo de colaboração, com assinatura da respetiva declaração de consentimento informado, 7 educadores sociais em exercício de funções, respetivamente, em projetos de mediação sociocultural, de desenvolvimento local, em programas de formação de adultos e em instituições particulares de solidariedade social (gerontologia social e animação sociocomunitária). Em coerência com a opção metodológica, o guião que serviu de base ao processo de produção de narrativas pessoais ficou decidido nesta sessão.

c. Processo de produção de narrativas durante dois meses (abril e maio de 20I9), com contactos regulares com a equipa de investigação, via correio eletrónico.

d. Recolha e análise das narrativas, devidamente codificadas e numeradas de acordo com a data de receção, de ni a n7, e trabalhadas através do processo de análise de conteúdo. Ou seja, através de um «método das categorias, espécie de gavetas ou rubricas significativas que permitem a classificação dos elementos 
de significação constitutivos da mensagem», apoiado em procedimentos sistemáticos e objetivos e funcionando "por operações de desmembramento do texto em unidades, em categorias segundo reagrupamentos analógicos» (Bardin, 2015: 38-39).

e. Reunião final com os participantes para reflexão conjunta, tendo por base os principais dados obtidos.

\subsection{Objetivos}

Considerando os argumentos e procedimentos explicitados, delineamos como objetivos operacionais desta investigação: i) Fundamentar a importância da ética na formação inicial dos pedagogos sociais; ii) Compreender de que forma os pedagogos sociais percecionam, conceptualizam e verbalizam os problemas/dilemas éticos emergentes do seu quotidiano profissional.

\section{Apresentação e discussão de resultados}

\section{I. Os educadores sociais na condição de autores}

Da análise das narrativas produzidas neste contexto de estudo e em conformidade com os objetivos enunciados, sobressaem desde logo, os aspetos identitários respeitantes às condições de autoria e de valorização profissional. Com efeito, o desejo de visibilidade e reconhecimento, institucional e social, surgem com especial evidência nas verbalizações dos participantes. Pode dizer-se que, tal como acontece com outros atores profissionais da área da educação, designadamente com os professores (Nóvoa, I995), os educadores sociais têm necessidade de "se dizerem e de se contarem». Uma necessidade demonstrada, sobretudo, no plano da comunicação oral. Na verdade, os participantes experienciaram e assumiram alguma dificuldade no que diz respeito à tradução escrita das suas inquietações e perceções. Valorizando o processo de produção de narrativas como oportunidade de expressão e reflexão, os participantes concluíram, de modo consensual, de que é importante desenvolver a dimensão de escrita profissional como meio de autoformação. Um dos participantes salientou mesmo a importância que os «diários profissionais» haviam assumido durante a sua formação académica, em particular durante o estágio. Consideradas neste contexto de pesquisa fundamentalmente como prática investigativa, as narrativas são reconhecidas pelos próprios atores como uma prática formativa e (trans)formativa, particularmente útil na reflexão sobre os problemas e os dilemas vividos no quotidiano profissional.

\subsection{Deliberar em contexto - inquietações e desafios}

Em concordância com os objetivos do estudo, os tópicos constantes do guião que serviu de base à produção das narrativas permitiram-nos agregar dois eixos de reflexão ou duas categorias de análise fundamentais: i) Consciência ético-profissional; ii) perceção sobre questões éticas e processos de decisão profissional. Relativamente 
à primeira categoria, foi possível constatar uma postura consensual de compromisso ético com a profissão. Recorrendo com frequência a palavras de autores que marcaram a sua formação académica, os participantes acentuaram o carácter estruturalmente relacional da atividade socioeducativa, destacando a importância de promoção de relações interpessoais positivas impulsionadoras de humanidade, criatividade e solidariedade. Esta preocupação relativa aos valores humanos constitui uma das marcas mais presentes e expressivas dos testemunhos dos educadores sociais que, de modo geral, se identificam como "profissionais dos direitos humanos», dando especial ênfase ao princípio de «respeito pelo outro enquanto outro». «Diariamente se nos impõe um exercício de alteridade, pois o outro poderia ser eu e se assim fosse gostaria que alguém me acolhesse de forma desinteressada apenas, e só, para me ajudar verdadeiramente» (n6). Ou, «tenho sempre dúvidas quando decido sobre a vida do ouTro [...] é singular é único e tem rosto» (n5). Consensualmente, reconhece-se que, quando se trata de uma atividade social e humana como a intervenção socioeducativa, "o receber, o atender e o escutar, ganham prioridade sobre o entender, o transmitir e o convencer» (Baptista, 20I7: I46-I47).

Como foi dito, afirmação do primado ético da relação interpessoal constitui uma nota dominante nos discursos dos participantes. «O nosso trabalho desenvolve-se através da relação humana, pelo que se torna fundamental regeremos a nossa prática profissional por condutas éticas» (n3). Uma exigência perspetivada, em primeiro lugar e, fundamentalmente, na relação com os educandos, mas extensiva também aos colegas de profissão, onde sobressai a referência ao trabalho colaborativo, à partilha de experiências e ao desafio de trabalhar em equipas multidisciplinares. Sendo de notar que entre as situações dilemáticas mais referidas surgem as que se referem a problemas de relação colegial e interprofissional, onde «muitas vezes se confundem os papéis e as funções, como, por exemplo, entre o trabalho de um assistente social e o trabalho de um educador social» (n3). Neste contexto, surge, com frequência, a interrogação sobre os limites da partilha profissional, remetendo para as questões de privacidade, confidencialidade e sigilo profissional. «Sempre que as crianças e jovens me confidenciavam questões mais pessoais e me pediam segredo [...] não podia em momento algum quebrar a confiança estabelecida» (n2). Ou, noutras situações, «são confidenciadas situações muito complicadas que tocam mesmo a ilegalidade e [...] tento gerir a situação caso a caso, porque nenhuma situação é igual à outra, nenhuma pessoa é igual à outra» (n6). Os casos descritos referem-se a situações em que, lidando com informações sensíveis sobre a vida de pessoas em situação de especial vulnerabilidade ou risco, surge a dificuldade decidir sobre o que dados se devem ou não partilhar, entre os técnicos diretamente envolvidos. O mesmo acontece quando se trata de reportar as situações e os problemas às autoridades institucionais. Nalguns casos, estas situações e estes problemas referiam-se mesmo ao comportamento de outros colegas. "Devemos ser solidários, mas há situações em que não podemos ficar calados e olhar para o lado, como na situação que descrevi e em relação à qual que tive mesmo que informar toda a equipa pedagógica do sucedido [...] inicialmente não sabia qual seria a melhor forma de agir, mas depois de uma reflexão mais aprofundada e de gerir os prós e os contras, considerei que deveria agir com ética e deontologia profissional» (n7).

Perante este tipo de testemunhos, quisemos por isso entender como é que, concretamente, os educadores lidavam com essas dificuldades e de que forma resolviam essas situações de maior tensão ou conflito. Desde logo surge em evidência, a impreparação 
inicial. «Era recém-licenciada [...] Não tinha nenhuma experiência profissional e não sabia como lidar» com a situação (nI) ou «confesso que senti que não tinha capacidades para tomar uma posição» (n2). Por vezes, recorre-se à ajuda de outros, colegas ou responsáveis institucionais, mas na maior parte das situações referidas, a decisão final é tomada de forma solitária e com algum sofrimento pessoal. Neste sentido, quisemos saber até que ponto a existência de documentos de regulação deontológica era útil. $\mathrm{Cu}$ riosamente, embora todos os praticantes tenham declarado conhecer o Código Deontológico dos Educadores Sociais portugueses das respetivas associações profissionais, nunca foi referido o recurso a estes documentos em situações de deliberação prática. «Considero o código bastante pertinente, no entanto, ainda não necessitei de recorrer a ele em nenhuma situação profissional» (ns) ou, também, quando é salientado que nunca «tive necessidade de recorrer a ele, embora já o tenha transmitido a colegas da educação social» $\left(\mathrm{n}_{3}\right)$. Citando, por exemplo, um dos documentos existentes, formula-se, de modo genérico, que a relação com os sujeitos aprendentes com quem se interage e com os quais é desempenhada a intervenção socioeducativa deverá centrar-se «numa postura profissional caracterizada por um sentido de responsabilidade» (APTSES, 20I6: $\operatorname{art}^{\circ}{ }^{\circ} I^{\circ}{ }^{\circ}$. Tal como foi sublinhado pelos nossos sujeitos, estes documentos fornecem algumas balizas, contribuindo como tal para o desenvolvimento da consciência ético-profissional, mas não resolvem os problemas de decisão em concreto. Ou seja, não subsituem a responsabilidade de cada ator refletir e decidir de forma adequada.

É importante notar que na maior parte dos casos que nos foram comunicados, as questões éticas referentes à relação entre educador-educando, reconhecida por todos como primacial do ponto vista ético, aparecem como indissociáveis das preocupações em torno da complexidade da relação profissional entre pares, evidenciando a necessidade de oportunidades de reflexão partilhada num quadro de reforço das competências colegais e interprofissionais. Outro dos vetores de análise a sublinhar prende-se com a dificuldade de deliberar em situação de modo «absolutamente profissional», isto é, «separando a pessoa do profissional» (Nóvoa, 1995). Nesse sentido, torna-se compreensível que «as pessoas tendem a ter opiniões diferentes, consoante a sua formação profissional, a sua vivência pessoal e familiar, a sua posição dentro da organização e o seu próprio carácter» (Banks e Nörh, 2008: 84). Como tal, tende a ser quase inevitável a remissão para valores de ordem familiar, cultural. Contudo, de acordo com o testemunho dos nossos participantes, os educadores sociais reconhecem a importância dos documentos orientadores da profissão, como as declarações de ética ou códigos deontológicos. Mas, tal como foi notado também, embora existam já documentos reguladores, constata-se que estes são ainda insuficientes no que toca à definição de padrões de desempenho específico. Por outro lado, em caso de conflito ou dúvida, os educadores não sabem exatamente a quem se devem dirigir na procura de apoio. Ou seja, não existem ainda Comissões ou Conselhos de Ética Profissional.

Em síntese, as narrativas dos participantes permitem inferir que foram identificadas as inquietações éticas (relação interprofissional, relação com os diferentes interlocutores da sua ação, deliberação prática, etc.), sendo claro que se interpelam, que questionam as suas práticas e ações socioeducativas, admitindo que elas comportam implicações para os educadores e para os educandos. Em nosso entender existe um traço comum, nas narrativas, quer nos valores assumidos que na assunção de responsabilidades e, em especial no tocante à deliberação em contextos profissionais. O desejo de maior colaboração colegial surge em evidência, reconhecendo que 
«no trabalho colaborativo com colegas de diferentes áreas disciplinares que encontramos a força e coragem para avançar» $\left(\mathrm{n}_{7}\right)$. Sendo, no entanto, de salientar a forma como são convocados valores como confiança, dignidade, confidencialidade, respeito, hospitalidade, alteridade e solidariedade entre pares. Ficaram ainda bem patenteadas as dificuldades em narrar as situações mais difíceis e suscetíveis de serem tomadas como "casos éticos», reforçando assim a necessidade de promoção de competências de escrita profissional e ética. Isto é, competências de escrita que permitam fazer justiça às situações num quadro de respeito pela dignidade humana, pelo direito à privacidade e à singularidade de cada um.

\section{Considerações finais}

Do processo de pesquisa global e, em particular, da análise e discussão dos dados expostos, ressalta a necessidade de reforço de uma cultura ético-profissional assente nos princípios da responsabilidade e da solidariedade colegial, com foco no aperfeiçoamento de competências ético-deontológicas que confiram maior segurança e autoridade aos processos de deliberação prática. E, deste modo, «satisfazendo as suas necessidades de conhecimento teórico, tempo de reflexão e aquisição de um modelo estrutural como ferramenta para análise e trabalho prático» (Banks e Nohr, 2008: I26). $\mathrm{Na}$ verdade, constatou-se que todos os participantes consideram a ética como uma necessidade de formação que facilita a deliberação prática, tendo sido apontada «a necessidade de construir uma atitude reflexiva, geradora de conhecimento» (n2), na consciência de que «têm contextos de ação muito diversificados e quando chegam ao terreno deparam-se com situações para as quais, muitas vezes, não são sensibilizados na formação inicial» (n6). Alguns dos participantes referiram mesmo a pertinência de unidades curriculares na formação inicial que permitam tratar as questões da ética profissional, no sentido de se anteciparem eventuais dilemas que se possam vir a encontrar na prática. Conclui-se assim que a ética constitui uma prioridade de formação. Por outro lado, «essa formação deveria incluir objetivos de conhecimento sobre a ética, a moral e a deontologia, mas sobretudo a capacitação para a reflexão pessoal e em grupo [...] sobre a sua prática diária» (Vargas, 20I2: 65). Ao mesmo tempo, e pelas razões que foram expostas, esta oferta formativa deverá contemplar a inclusão da escrita reflexiva utilizando, por exemplo, os «diários profissionais». Considera-se que quando se escreve é necessário decidir o que escrever, organizar ideias e "produzir relatos reflexivos verbais ou por escrito de situações que implicam questões éticas é uma boa maneira de encorajá-los a adquirir esta capacidade» (Banks e Nohr, 2008: 60). Só a construção de uma sabedoria prática, situada no horizonte concetual de uma ética aplicada, poderá construir a profissionalidade, de todos e de cada um, assumindo-se a necessidade de aperfeiçoamento profissional ininterrupto, indo assim, deste modo, ao encontro das preocupações e do compromisso ético dos educadores sociais.

\section{Referências}

Associação Portuguesa de Técnicos Superiores de Educação Social (aptses). (20i6). Código Deontológico do Técnico Superior de Educação Social. Obtido em http://www. aptses.pt/static/CODIGODEONTOLOGICO.pdf. 
BANKs, S. (2008). Utilização de diários como encorajamento à reflexão ética durante o estágio. In S. BAnks e K. Norh, Ética prática para as profissões do trabalho social (pp. 59-70). Porto: Porto Editora.

Banks, S. e Nohr, K. (2008). Ética prática para as profissões do trabalho social. Porto: Porto Editora.

Baptista, I. (2005). Dar rosto ao futuro. Educação como compromisso ético. Porto: Profedições.

Baptista, I. (2006). Problemas, dilemas e desafios éticos na intervenção sócio-educativa. In Actas do Encontro de Intervenção Social: saberes e contextos. Porto: Escola Superior de Educação de Paula Frasinetti.

Baptista, I. (2008). Pedagogia Social: uma ciência, um saber profissional, uma filosofia de acção. Cadernos de Pedagogia Social, 2, 7-30.

Baptista, I. (20I2). Ética e educação social. Pedagogía Social. Revista Interuniversitaria, I9, 37-49.

Bardin, L. (2015). Análise de conteúdo (5. ${ }^{\mathrm{a}}$ ed.). Lisboa: Edições 70.

Baptista, I. (20I7). Ética do rosto e profissionalidade docente. In A. F. Silva, L. R. Ferreira e R. T. Ens, Políticas de expansão universitária. Reflexões sobre a vida acadêmica (pp. 145I6I). Brasil: Editora PUCPREsss. Pontifícia Universidade Católica do Paraná.

BAPTiSTA, I. (20I6). Para uma fundamentação antropológica e ética da educação: a escola como lugar de hospitalidade. EDUCA. International Catholic Journal of Education, 2, 203-212.

Campbell, E. (20II). Teacher Education as Missed Opportunity in the Professional Preparation of Ethical Practitionners. In L. Bondi, D. Carr, C. Clark e C. Clegg (orgs.), Towards Professional (pp. 8I-89). Surrey: Ashgate Publishing Limited.

Camões, A. (20I8). Formação Continua e Ethos Profissional. O Caso dos Educadores Sociais em Portugal. Tese de Doutoramento. Porto: FEP/Universidade Católica.

Carvalho, A. e Baptista, I. (2003). A pedagogia social na revalorização do estatuto antropológico do sujeito. Pedagogía Social. Revista Interuniversitaria, I0, I8I-192.

Carvalho, A. e Baptista, I. (2004). Educação social. fundamentos e estratégias. Porto: Porto Editora.

Díaz, M. C. e Carreras, J. S. (20I2). Por uma ética situacional. Pedagogía Social. Revista Interuniversitaria, $19, \mathrm{I3}-33$.

Levinas, E. (1998). Totalidade e infinito. Lisboa: Edições 70.

Nóvoa, A. (1995). Vidas de professores (2. ${ }^{a}$ ed.). Porto: Porto Editora.

Pineau, G. e Le Grand, J. L. (2002). Les histoires de vie (3. ${ }^{a}$ ed.). Paris: Presses Universitaires de France.

Schön, D. (1995). Formar professores como profissionais reflexivos. In A. NóvoA, Os professores e a sua formação (pp. 77-9I). Lisboa: Publicações D. Quixote.

Schön, D. (200o). Educando o profissional reflexivo. Porto Alegre: Artemed.

Vargas, L. P. (20I2). Deontología y código deontológico del educador social. Pedagogía Social. Revista Interuniversitaria, I9, 65-79. 